\title{
Characterising Childhood Blackwater Fever and Its Clinical Care at Two Tertiary Hospitals in Eastern Uganda
}

\section{George Paasi}

Mbale Clinical Research Institute

Carolyne Ndila

Mbale Clinical Research Institute

William Okiror

Mbale Clinical Research Institute.

Cate Namayanja

Busitema University

Benard Phelan Okalebo

Mbale Clinical Research Institute

Grace Abongo

Mbale Clinical Research Institute

Florence Alaroker

Soroti Regional Referral Hospital

Julian Abeso

Mbale Regional Referral Hospital

Andrew Kasoro

Mbale Regional Referral Hospital

Francis Okello

Busitema University

Peter Olupot-Olupot ( $\nabla$ polupotolupot@yahoo.com )

Busitema University https://orcid.org/0000-0002-5757-609X

\section{Research}

Keywords: Blackwater fever, clinical characteristics, routine care, Eastern Uganda

Posted Date: May 25th, 2021

DOI: https://doi.org/10.21203/rs.3.rs-545832/v1 
License: (c) (i) This work is licensed under a Creative Commons Attribution 4.0 International License. Read Full License 


\section{Abstract \\ Background}

In eastern Uganda, reports suggest that cases of Blackwater Fever (BWF) are on the rise. We summarise the base-line characteristics and routine care available to patients with BWF presenting at two tertiary hospitals in Eastern Uganda prior to the Phase I/II trial on use of paracetamol for acute kidney injury in children with BWF (PARIST; ISRCTN84974248).

\section{Methods}

This was a retrospective descriptive study for the period January - December 2018 for children admitted with a clinical diagnosis of BWF at Mbale and Soroti Regional Referral Hospitals in Eastern Uganda. Data on sociodemographic and clinical characteristics, routine in-patient care and outcomes were abstracted using a customised study proforma and analysed using STATA.

\section{Results}

We obtained 9578 admission records during the study period, of which 1241 (13.0\%) were admitted with a diagnosis of BWF. The median age was 60 months (IQR 36-90). Male: female ratio was 1.5:1. More cases of BWF $682 / 1241$ (55.0\%) were in children > 5 years compared to $559 / 1241(45.0 \%) \leq 5$ years $[95 \%$ $\mathrm{Cl}(0.41-0.59) ; P=0.0002]$. The common symptoms included fever $1109 / 1241$ (89.4\%), vomiting $599 / 1241$ (48.3\%) and abdominal pain 494/1241 (39.8\%). Conversely, the common signs recorded were clinical pallor 742/1241 (59.8\%), clinical jaundice 369/1241 (29.7\%), fever 332/1241 (26.7\%) and prostration 231/1241 (18.6\%). In addition, abdominal tenderness was documented in 120/1241 (9.7\%), splenomegaly in 122/1241 (9.8\%) and hepatomegaly in 86/1241 (6.9\%). Case records with BWF were more in the second half of the year with a peak in the months of July and September. 510/1241 (41.1\%) were treated with antimalarial drugs mainly parenteral Artesunate 501/510 (98.2\%). 660/1241(53.2\%) of the patients were managed with antibiotics mainly parenteral ceftriaxone $616 / 660$ (93.3\%). There were $426 / 1241$ (34.3\%) patients who received blood transfusion during admission. Clinicians used steroid treatment in 388/1241 (31.3\%), mainly parenteral hydrocortisone 370/388 (95.4\%).

\section{Conclusions}

BWF accounted for $13 \%$ paediatric hospital admissions in the region. It was predominant in children $>5$ years of age. It typically presents with passing dark urine, fever, abdominal pain, clinical jaundice and pallor. Locally there are no treatment guidelines for BWF. These data provide background data useful for future studies on BWF in the region. 


\section{Background}

Blackwater fever (BWF) a clinical condition characterized by an acute intravascular haemolysis resulting in passing dark, tea or Coca-Cola coloured urine $(1,2)$, is almost exclusive to $P$. falciparum malaria (3). Historically, the case definition included: Caucasian who had lived or visited malaria endemic area for a long time ( $>3$ months) without previous exposure to malaria and were taking quinine in inappropriate dose or schedule for malaria prophylaxis and/or treatment (4-6). The initial attack of malaria complicated with BWF would typically present with loin pain, abdominal discomfort, restlessness, vomiting, diarrhoea, polyuria followed by oliguria and passage of dark red or black urine. Signs included tender hepatosplenomegaly, profound anaemia and jaundice $(1,7-10)$. Since then, however, use of such case definitions in the African populations have been done with mixed outcomes across geographical or population strata. For instance, prevalence and mortality range from $6-59 \%(11-14)$ and $4.4-25.3 \%$ (15-17) respectively. BWF studies in African children are complex $(7,11,18)$. Adult case definitions are considered inappropriate for children, where malaria related renal failure was considered a rare clinical feature (19-22). As a contrast, BWF in children is often at initial stages of illness as opposed to adults who manifest it at the end stages of malaria disease (10). Moreover, there is a low clinical index of suspicion among attending clinicians and limited capacity to investigate the differentials of dark urine in resource-limited settings. To date, there is a paucity of recent descriptions on BWF, which focus on children in Africa $(7,11,18)$. Most referenced data describing the phenomenon of BWF report varying prevalence of $6-48 \%(11,12)$ and $11-59 \%(13,14)$ of patients with severe malaria respectively. However, most of these were observational studies in adult series involving malaria non-immune patients. Even with a recognised malaria epidemiological transition $(23,24)$, with reports of malaria reducing $(25-29)$, malaria remains endemic in some regions and countries including Uganda (30). In such settings childhood severe malaria studies suggests a high prevalence of BWF. For instance, 25.3\% in Kinshasa in DRC (31), 19.1\% in Ibadan, Nigeria (32) and 17.2\% in Togo between 2000 and 2002 (16) in contrast to a lower prevalence reported in a large randomised controlled trial of Artesunate v Quinine (AQUAMAT) in African children $<15$ years of age with severe malaria ( $n=5,246$ at 10 sites in nine countries) that indicated BWF in 237/5,426 (4.4\%) (33). Earlier studies in Eastern Uganda reported a high frequency of BWF $14.5 \%$ and $21.8 \%$ at Mbale and Soroti Regional Referral Hospitals (FEAST Trial; ISRCTN69856593) (34). As with AQUAMAT study, the FEAST study was on a highly selected group of patients, which were not representative of the facility-based disease burden. Speculation on the cause of the notable increase in frequency of BWF in this region has been linked to a possible change in the malaria treatment protocols in the last decade (34), but have not been proven. It is also possible that changes to local parasite population to a strain with a greater propensity to cause BWF are in play as hypothesised by other studies $(35,36)$, but this has also not been studied in the region. It is possible that BWF in the region is multifactorial and that is conceivably the reason for high number of cases. In this study, we report BWF in general admissions in Eastern Uganda.

\section{Methods And Materials}




\section{Study Area and Sites}

The study was carried out on the admission medical records at the paediatric units at Mbale and Soroti Regional Referral Hospitals (RRH) in Eastern Uganda. Both facilities are government run, not for profit and charge-free hospitals. Mbale RRH is located at the heart of Mbale City, $214 \mathrm{KM}$ to the east of the Capital City Kampala while Soroti RRH is located at the centre of Soroti City; $100 \mathrm{KM}$ north-east of Mbale City. At both facilities, four major general specialties: surgery, internal medicine, obstetrics and gynaecology, and paediatrics are offered. Mbale RRH is larger with 470 bed capacity, compared to Soroti RRH with 274 bed, but they have comparable proportions of paediatric bed capacity at $95(20.2 \%)$ vs. 64 (23.4\%) respectively. The recent annual paediatric caseload at Mbale RRH on average is 10,000 admissions from a catchment of 16 districts with a population of 4.5 million. The geographical catchment area for Mbale RRH (Elgon sub region) is hilly and situated in the range 980 to $1,800 \mathrm{~m}$ above sea level. Conversely, Soroti RRH admits approximately 6,000 children annually from a catchment population of 2.9 million in 9 districts. Its catchment geographical area (Teso sub region) is generally flat and most districts are $<1000 \mathrm{~m}$ above sea level.

\section{Study design}

This was a retrospective descriptive study. Records for children aged 2 months to 15 years in the paediatric units at the two hospitals with admission diagnosis of BWF for the period January 1, 2018 to December 31, 2018 were studied.

\section{Study Procedures}

The paediatrics admission registers were used to identify all the children who presented with a diagnosis of BWF. BWF was diagnosed clinically as passing dark/tea/Coca-Cola coloured urine and corresponding urine colour grade $\geq 5$ on the Hillmen Urine Colour Chart (37) (Fig. 1). On admission, the axillary temperature was measured with a digital thermometer. Fever (axillary temperature $\geq 37.50 \mathrm{C}$ ) was further categorized as mild fever (37.5-37.90C), moderate fever [(38.0-38.50C) and severe fever (>38.50C). Prostration was defined as inability to sit upright / stand unsupported /breastfeeding age $<6$ months. Comorbidity was defined as 'any distinct additional clinical entity that has coexisted or that may occur during the clinical course of a patient who has BWF. Level of consciousness was assessed using the AVPU score ('Alert,' 'Responding to Voice,' 'Responding to Pain only,' or 'Unresponsive'). Clinical jaundice was yellowing of mucous membranes noted in sufficient daylight (38). Clinical assessment of pallor of mucous membranes indicated the degree of pallor (either none, mild, moderate or severe). The admitting clinician (Clinical officer or medical officer) carried out an assessment of pallor and determined whether they felt the clinical severity of pallor would warrant transfusion.

Trained research assistants retrieved the case records and extracted data on socio-demographic characteristics including gender, age and ethnicity. They further obtained admission data on presenting symptoms, duration of illness, physical signs, co-morbidities and treatment received. Records with 
missing study variables on age, gender, illegible files, those outside the study period and age range were excluded.

\section{Use of the Hillmen Urine Colour Chart}

At admission, patients with a history of passing dark urine during the course of their current illness were initially assessed by clinicians based on history, an inquiry about the child passing dark urine, defined as Coca-Cola or tea coloured urine on the day of admission was made. Furthermore, asking the parent/guardian to indicate the grade (by pointing) at the colour against the Hillmen Urine Colour Chart (HUCC) (Fig. 1) qualitatively assessed the urine colour. The HUCC had 10 colour codes ranging from mild yellow (colour code 1) to black (colour code 10). A probable and confirmed diagnosis of BWF/dark urine was made at admission. The patient/guardian was first asked to recall and match the colour of urine passed by their child on the day of admission to a colour on the HUCC. If available, urine was collected from the child using paediatric urine collection bags before it was transferred into the urine collection bottle. The study clinician then matched the urine colour to the corresponding score on the HCC scale. Children with clinician-witnessed urine or patient/guardian matched the colour of urine passed by their child on the day of admission corresponding to $\mathrm{HCC}>5$ on the chart were confirmed to have BWF/dark urine syndrome. These were the eligible patients for the study. For easy access and efficient use of the $\mathrm{HCC}$, charts were displayed both in the patient admission area and in the ward.

\section{Data management and statistical analyses}

The data was entered into MS Excel, exported and analysed using STATA (version 14.0, College Station, Texas 77845 USA). All qualifying records for the period of study chosen were included. Initial descriptive and univariate analyses were carried out on the data. Means and standard deviations (SDs) were determined for normally distributed continuous variables and medians and interquartile ranges (IQRs) for non-normally distributed variables. Proportions and percentages were determined for categorical variables. Study participants were stratified by age ( $\leq 5 y e a r s$ and $>5$ years) and gender. Between group differences were assessed using Pearson's $\chi 2$. The difference was considered significant at $P<0.05$.

\section{Results}

During the 12-month study period, 9578 records of children admitted to the Paediatric Acute Care Unit (PACU) at the two hospitals were retrieved. Of these 1308 (13.7\%) of the records had BWF. Excluded were $67 / 1308(5.1 \%)$ records because of the missing data on key variables. The remaining 1241/9578 (13.0\%) were eligible records and included in the study.

\section{Sociodemographic characteristics}

The overall median age in this study population was 60-month; range 4-180 months (IQR 36-90). A male preponderance (1.5:1 male to female ratio) was observed. $559(45.0 \%) \leq 5$ years vs $682(55.0 \%)>5$ years [95\% $\mathrm{Cl}(0.41-0.59) ; P=0.0002]$. The socio-demographic characteristics are summarised in table 1.0 . 
Table 1

Socio-demographic characteristics of

BWF cases.

\begin{tabular}{|lll|}
\hline Demographics & Freq. & Percent \\
\hline Age & & \\
$\leq 5$ & 559 & 45.04 \\
$>5$ year & 682 & 54.96 \\
Gender & & \\
Female & 501 & 40.4 \\
Male & 740 & 59.6 \\
\hline Ethnicity & & \\
\hline ITESOT & 691 & 55.7 \\
MUGISHU & 205 & 16.5 \\
KUMAM & 133 & 10.7 \\
\hline OTHERS & 212 & 17.1 \\
\hline
\end{tabular}

\section{Clinical characterization of BWF.}

The clinical features of BWF participants stratified by age category are summarized in Table 1.1. Besides all patients presenting with passing dark urine /tea-coloured urine, most of the patients also commonly presented with high fever 1109 (88.7\%), vomiting 599 (48.3\%) and abdominal pain 494 (39.8\%). The common clinical signs at presentation included clinical pallor 742 (59.8\%), clinical jaundice 369 (29.7\%), fever on examination 332 (26.8\%) and prostration 231 (18.6\%). In addition, abdominal signs of abdominal tenderness 120 (9.7\%), splenomegaly 122 (9.8\%) and hepatomegaly $86(6.9 \%)$ were recorded.

Compared to $\leq 5$ years, the $>5$ years significantly presented with symptoms of abdominal pain (320 (46.9\%) vs $174(31.1 \%) P<0.001)$, chest pain (72 (10.6\%) vs $32(5.7 \%) P=0.013)$, vomiting $(364$ (53.4\%) vs $235(42.0 \%) P=0.031)$ and headache $(222(32.6 \%)$ vs $87(15.6 \%) P<0.001)$. The $>5 y e a r s$ patients were more likely to be anaemic $P=0.002$ [moderate (135 (19.8\%) vs $75(13.4 \%)$ ] and severe pallor [204 $(29.9 \%)$ vs $126(22.5 \%)$ ]. They had features of impaired perfusion/ delayed capillary refill time $P=0.023$ [2-3 sec (125 (19.8\%) vs 81 (13.4\%)] and > $3 \mathrm{sec}$ [51 (7.5\%) vs 21 (1.7\%)], clinical jaundice [246 (36.1\%) vs $123(22.0 \%) P=0.000$ ] and abdominal tenderness [78 (11.4) vs $42(7.5 \%) P=0.02$ ].

On the other hand children $\leq 5$ years in comparison to the $>5$ years significantly presented with symptoms of difficult breathing (45 (8.1\%) vs $27(4.0 \%) P=0.000)$, fast breathing (83 (14.8\%) vs 72 (10.6\%) $P=0.002)$ and convulsions (49 (8.8\%) vs $23(3.4 \%) P=0.000)$. The $\leq 5$ years patients were more likely to have severe fever (temperature $>38.5) p=0.047(25(4.5 \%)$ vs $25(3.7 \%))$ and altered level of 
consciousness AVPU score of VPU (V (21 (3.8\%) vs 21 (3.1\%)), P (15 (2.7\%) vs 14 (2.1\%)) and U (5 (0.9\%) vs $0(0 \%))$. 
Table 2

The baseline clinical characteristics of BWF cases stratified by age.

\begin{tabular}{|c|c|c|c|c|}
\hline Symptoms & $\leq 5$ & $>5$ year & Total & $P$-value \\
\hline $\mathrm{N}$ & $559(\%)$ & $682(\%)$ & $1,241(\%)$ & \\
\hline Fever & $471(84.3)$ & $638(93.5)$ & 1109 (89.4) & 0.711 \\
\hline Difficulty in breathing & $45(8.1)$ & $27(4.0)$ & $72(5.8)$ & $<0.001$ \\
\hline Fast breathing & $83(14.8)$ & $72(10.6)$ & $155(12.5)$ & 0.002 \\
\hline Hand pain & $45(8.1)$ & $81(11.9)$ & $126(18.5)$ & 0.137 \\
\hline Foot pain & $49(8.8)$ & $75(11.0)$ & $124(18.2)$ & 0.537 \\
\hline Abdominal pain & $174(31.1)$ & $320(46.9)$ & $494(39.8)$ & $<0.001$ \\
\hline Chest pain & $32(5.7)$ & $72(10.6)$ & $104(8.4)$ & 0.013 \\
\hline Vomiting & $235(42.0)$ & $364(53.4)$ & $599(48.3)$ & 0.031 \\
\hline Nausea & $63(11.3)$ & $98(14.4)$ & $161(13.0)$ & 0.465 \\
\hline Convulsions & $49(8.8)$ & $23(3.4)$ & $72(5.8)$ & $<0.001$ \\
\hline Headache & $87(15.6)$ & $222(32.6)$ & $309(24.9)$ & $<0.001$ \\
\hline Signs & $\leq 5$ & $>5$ year & Total & $P$ value \\
\hline $\mathrm{N}$ & 559 & 682 & 1241 & \\
\hline Abdominal tenderness & $42(7.5)$ & $78(11.4)$ & $120(9.7)$ & 0.02 \\
\hline Clinical jaundice & $123(22.0)$ & $246(36.1)$ & $369(29.7)$ & $<0.001$ \\
\hline Splenomegaly & $55(9.8)$ & $67(9.8)$ & $122(9.8)$ & 0.993 \\
\hline Fever on examination & & & & 0.047 \\
\hline Mild (37.5-37.9) & $41(7.3)$ & $45(6.6)$ & $86(6.9)$ & \\
\hline Moderate (38.0-38.5) & $74(13.2)$ & $122(17.9)$ & $196(15.7)$ & \\
\hline Severe $(>38.5)$ & $25(4.5)$ & $25(3.7)$ & $50(4.0)$ & \\
\hline Capillary refill time (seconds) & & & & 0.023 \\
\hline $2-3 \mathrm{sec}$ & $81(14.5)$ & $125(18.3)$ & $206(16.6)$ & \\
\hline$>3 \mathrm{sec}$ & $21(1.7)$ & $51(7.5)$ & $72(5.8)$ & \\
\hline Pallor & & & & 0.002 \\
\hline Mild & $84(15.0)$ & $118(17.3)$ & $202(16.3)$ & \\
\hline Moderate & 75 (13.4) & $135(19.8)$ & $210(16.9)$ & \\
\hline
\end{tabular}




\begin{tabular}{|lllll|}
\hline Symptoms & $\mathbf{5}$ & $\mathbf{>} \mathbf{5}$ year & Total & $P$-value \\
\hline Severe & $126(22.5)$ & $204(29.9)$ & $330(26.6)$ & \\
Level of Consciousness & & & & 0.023 \\
Verbal & $21(3.8)$ & $21(3.1)$ & $42(3.8)$ & \\
Pain & $15(2.7)$ & $14(2.1)$ & $29(2.3)$ & \\
Unconscious & $5(0.9)$ & $0(0)$ & $5(0.4)$ & \\
Prostrated & $88(15.7)$ & $143(21.0)$ & $231(18.6)$ & 0.222 \\
Acidotic breathing & $10(1.7)$ & $6(0.9)$ & $16(1.3)$ & 0.11 \\
\hline
\end{tabular}

Overall, there were no significant differences in the clinical characteristics observed between the males and females.

\section{Pattern of distribution of BWF cases in 2018}

Noticeably, presentation with BWF was more in the second half of the year in 2018 with a peak in the month of July to September (Fig. 2). The patterns of distribution of BWF cases disaggregated by sex and age category revealed an overall higher number of BWF cases above 5 years compared to under 5 years for the females while the number of BWF cases under 5 was slightly higher than the above 5 for the males in the two age categories. For both the peak in the number of cases was reported in the second half of the year with the highest being the month of August. (Fig. 3).

- Figure 2 Pattern of monthly admissions of BWF cases in 2018

- Figure 3. Seasonal variation of BWF cases by sex and age category in 2018.

\section{Routine treatment received by BWF patients}

The routine treatment of patients with BWF is summarized Table 2. 510/1241 (41.1\%) were treated with antimalarial drugs mainly parenteral Artesunate 501/1241 (40.4\%). There were 426/1241 (34.3\%) patients who received blood transfusion during this current illness of these, 281/1241(22.6\%) received 1 blood transfusion and 145/1241(11.6) received $\geq 2$ blood transfusion. 660/1241(53.2\%) of the patients were managed with antibiotics mainly parenteral ceftriaxone 616/1241 (49.6\%). Surprisingly, a considerable number of patients $388 / 1241$ (31.3\%) were treated with steroids mainly parenteral hydrocortisone $370 / 1241$ (29.8\%). 
Table 3

Routine treatment received by BWF patients in this admission grouped by age category

\begin{tabular}{|llll|}
\hline Treatment & Overall, N (\%) & Age category & \\
\hline Total & & $\leq 5 y e a r s ~(\%)$ & $>5 y e a r s ~(\%)$ \\
\hline Antimalarial & $1241(100)$ & $559(100)$ & $682(100)$ \\
\hline Artesunate & & & \\
\hline Coartem & $501(40.4)$ & $220(30.4)$ & $281(41.2)$ \\
\hline Fansidar & $2(0.2)$ & $0(0)$ & $2(0.3)$ \\
\hline Quinine & $5(0.4)$ & $0(0)$ & $5(0.7)$ \\
\hline Blood transfusion & $2(0.2)$ & $1(0.2)$ & $1(0.1)$ \\
\hline 1 blood transfusion & $281(22.6)$ & $127(22.7)$ & $154(22.6)$ \\
\hline 2 blood transfusions & $106(8.5)$ & $44(7.9)$ & $62(9.1)$ \\
\hline$\geq 3$ blood transfusions & $39(3.1)$ & $16(2.9)$ & $23(3.4)$ \\
\hline Antibiotics & & & $13(1.9)$ \\
\hline ceftriaxone & $616(49.6)$ & $269(48.1)$ & $347(50.9)$ \\
\hline Ampicillin & $24(1.9)$ & $14(2.5)$ & $10(1.5)$ \\
\hline Gentamycin & $20(1.6)$ & $9(1.6)$ & $11(1.6)$ \\
\hline Steroids & & & \\
\hline Hydrocortisone & $370(29.8)$ & $132(23.6)$ & $238(34.9)$ \\
\hline Prednisolone & $18(1.5)$ & $5(0.9)$ & \\
\hline
\end{tabular}

\section{Discussion}

Our large retrospective study provides a contribution to the descriptions of paediatric BWF in malaria high transmission settings in Eastern Uganda. The prevalence rate of BWF of 13\% reported in our study was comparable to earlier descriptions of BWF in malaria endemic settings $(1,2,31,39-41)$.

The higher frequency of BWF in children aged $>5$ years, $682 / 1241$ (55.0\%) compared to $\leq 5$ years, $559 / 1241(45.0 \%) ;[$ [95\% $\mathrm{Cl}(0.41-0.59) ; \mathrm{P}=0.0002]$, observed in this study was consistent with previous reports from Kinshasa in DRC, a similarly holo- hyperendemic malaria setting (31). This has led to questioning the link between BWF and malaria. If malaria was a direct driving factor, then children aged > 5 years who are expected to have acquired malaria immunity $(1,18,42,43)$, would be resilient to BWF. On 
the other hand, if it was an innate factor then either more of the $\leq 5 y e a r$ old children or a similar proportion across the various age strata would have been observed with BWF. Therefore, greater understanding is still needed to elucidate the aetiopathophysiology of BWF.

We found the clinical features in childhood BWF were similar to the adult BWF case definitions (10), the cases typically presented with passing dark urine (1241/1241 (100\%)), high grade fever (332/1241 (26.8\%)), clinical jaundice (369/1241(29.7\%)), pallor (742/1241(59.8\%)) and abdominal pain $(494 / 1241(39.8 \%))$. Severity features reported in this study including unconsciousness $(5(0.4 \%))$, convulsions (72/1241(5.8)), prostration (231/1241(18.6\%)), severe pallor/anaemia (330/1241(26.6\%)) and respiratory distress/acidotic breathing $(16 / 1241(1.2 \%))$ seem to be similar to those reported in severe malaria series given the fact that BWF is also a form of severe malaria $(38,44-47)$. Of specific significance was the finding of abdominal pains (494/1241(39.8\%)) and tenderness (120/1241(9.7\%)) in this study population. Few data, if at all any, have described this phenomenon in relation to severe malaria or specifically BWF in African children. We think the ischaemic process following sequestration of parasitized red blood cells $(48,49)$ in the small blood vessels supplying mesentery may possibly lead to mesenteric infarction and thus the abdominal pain/tenderness.

A number of speculations have been made to try and explain high prevalence of BWF in these settings. For instance, the coincidence of increased cases of BWF with a roll out of Artemesinin Combination Therapies (ACTs) for control of malaria has postulated but has not been well studied (34). Elsewhere, lumefantrine, a key drug in first line ACTs has been implicated in the causation of BWF, but descriptions in African children have not been done. Similarly, the role of repeated exposure to other antimarials $(18,31$, 39), and blood transfusions in the causation of BWF in children have also not been explored in these settings. High rates of index and repeat blood transfusions, in a phenomenon similar to isoimmunisation in mother-baby situation may be underlying in some of the massive haemolysis observed in these populations, but needs further research. Conversely, whereas past epidemiological studies have indicated that the interaction between host response to repeated malarial attacks, use of antimalarials, and possibly glucose-6-phosphate dehydrogenase (G6PD) deficiency are trigger factors (50), more recent descriptions in Eastern Uganda do not associate the phenomenon to G6PD deficiency(34). Alternatively, other scholars have argued that the possible cause is likely a recent change in the malaria parasite population towards a strain with a greater propensity towards causing $\operatorname{BWF}(35,36)$.

The seasonal trend of BWF admissions in 2018 showed one peak in the months of July to September. Eastern Uganda receives moderate rainfall with annual rainfall averages ranging from $1100-1200 \mathrm{~mm}$ and this is distributed between two seasons (March to July and September to November) (51). A malaria surveillance study done in all the regions of Uganda between 2015 to 2019 showed the highest peaks in monthly trends in regional malaria incidence rates were in June-July, highest in June, 2017 (Range: 13.4- 95.6 cases per 1000) and July, 2019 and the lowest troughs in February-March of each calendar year(52). Teso region home to one of the study sites (Soroti RRH) was one of the regions that persistently recorded the highest monthly incidence rates across the entire study duration (52). Possibly, the malaria incidence rate peaks of June - July of 2018 may have coincided with the peak in BWF admissions 
reported in this study between July and September suggesting either similar risk factors or a cause-effect relationship between BWF and malaria in this setting.

Understanding paediatric BWF in Africa is very important for informing treatment options and plans. Currently, there are no specific treatment and prevention remedies for BWF. According to the Uganda clinical guidelines, all cases are treated as severe malaria and respective supportive treatment such as blood transfusion is given (53), which is plausible. However, with no specific management guidelines for BWF, inconsistences exist in patient care owing to the differences in clinician expertise/training,

experience and acumen. This explains the variability in treatment reported in this study. The inappropriate use of antimalarial and antibiotics especially second line cephalosporin (ceftriaxone 616/1241 (49.6\%)) poses a threat of antimicrobial resistance. Surprisingly, a considerable number of patients 388/1241 $(31.3 \%)$ were treated with steroids mainly parenteral hydrocortisone 370/1241 (29.8\%) this increases the likelihood of steroid induced side effects. Therefore, there is need to develop adjuvant treatment specific to the pathophysiology of BWF to contribute to better outcomes. In addition, the high frequency of blood transfusions among children with BWF suggests efforts and strategies should be focused on preventing severe anaemia in the post discharge period including the use of haematinics and insecticide treated mosquito nets $(54,55)$.

This retrospective study design had some limitations. Mainly, the diagnosis of BWF was done clinically using the Hillmen urine colour chart. No real-time laboratory investigations were done to elucidate the aetiopathophysiology of BWF in children including acute kidney injury, one of the unique features of BWF in children (56). There was no data on post discharge status and as such, repeat or late onset BWF which usually occurs after 28days was not reported, yet these data are important in understanding of the complete disease picture. Nonetheless, this study was pragmatic and done at two high volume tertiary hospitals. It made use of a large sample size, which imparts significant strength to the study findings and was based on the diagnostic capabilities of health facilities in resource-limited settings used for routine care. Therefore, this study highlights the socio-demographic characteristics, clinical features and routine care of BWF patients at two tertiary hospitals in Eastern Uganda. We describe these data in Eastern Uganda ahead of a Phase I/II trial on use of paracetamol for acute kidney injury in children with BWF (PARIST; ISRCTN84974248).

\section{Conclusion}

In conclusion, BWF remains an important cause of paediatric admissions in eastern Uganda, it accounted for $13 \%$ admissions. Its predominance in children $\geq 5$ years suggests a greater role of acquired factors compared to that of inherited causes. Patients typically present with passing dark urine, fever, clinical jaundice, pallor and abdominal pain. There are no management guidelines for BWF locally and as such, patient care is supportive.

\section{Declarations}




\section{Ethics approval and consent to participate}

Ethical approval for the study was obtained from the Mbale Regional Referral Hospital Research \& Ethics Committee (MRRH-REC; approval number MRRH-REC OUT 0039/2019). A waiver of informed consent was granted on grounds of this being a retrospective study. Written permission to conduct the study at each of the sites were obtained from Mbale and Soroti RRH leadership.

\section{Consent to Publish}

The Mbale Clinical Research Institute (MCRI; www.mcri.ac.ug), a research entity affiliated to the Uganda National Health Research Organization (UNHRO), approved the publication of this manuscript.

\section{Availability of data \& materials}

The study data are available by request to the corresponding author.

\section{Competing interest}

The authors declare no competing interest.

\section{Funding}

This publication was produced by MEPIE which is part of the EDCTP2 programme supported by the European Union (grant number TMA 2016 SF 1514-MEPIE Study). The views and opinions of authors expressed herein do not necessarily state or reflect those of EDCTP.

\section{Author contribution}

P-OO conceived and supervised the study. GP collected the data and wrote the first draft of the manuscript. $\mathrm{CN}$ designed the database and together with FO conducted the data analysis. GA data curation. CN, GA, WO, P-OO, WO, BPO, FA, JA and AK participated in development of the data collection tool, collection of data and writing the manuscript. All authors contributed to editing and approval of the final submission.

\section{Acknowledgements}

We do acknowledge Mbale and Soroti Regional Referral Hospitals, Mbale Clinical Research Institute and all staff at these centres for their various contributions to this work.

\section{References}

1. Gobbi F, Audagnotto S, Trentini L, Nkurunziza I, Corachan M, Di Perri GJEid. Blackwater fever in children, Burundi. 2005;11(7):1118. 
2. O'Donnell A, Weatherall D, Taylor A, Reeder J, Allen SJTotRSoTM, Hygiene. Muscle cell injury, haemolysis and dark urine in children with falciparum malaria in Papua New Guinea. 2006;100(9):817-25.

3. Bodi JM NC, Longenge RL Blackwater fever in Congolese children: a report of clinical, laboratory features and risk factors. . Malar J. 2013;12:205.

4. Janssens P. Blackwater fever. Health in Central Africa since 1885; past, present and future. 1997.

5. Lesieur O, Dudeffant P, Courtiade B, Haglund P. Blackwater fever: a fatal case. Intensive care medicine. 1997;23(11):1188.

6. Maharaj D, McDonald G, Dobbie J. Splenectomy and blackwater fever. British journal of haematology. 1982;51(4):663-4.

7. Bruneel F, Gachot B, Wolff M, Regnier B, Danis M, Vachon F, et al. Resurgence of blackwater fever in long-term European expatriates in Africa: report of 21 cases and review. Clin Infect Dis. 2001;32(8):1133-40.

8. George CR. Blackwater fever: the rise and fa II of an exotic disease. . Journal of nephrology,. 2009;22 $120-8$.

9. Tran TH, et al. Blackwater fever in southern Vietnam: a prospective descriptive study of 50 cases. . Clinical infectious diseases : an official publication of the Infectious Diseases Society of America. 1996;23(6):1274-81.

10. WHO. Severe Malaria. Tropical Medicine and International Health. 2014;volume 19:7-131.

11. Kouame K, et al.,. Severe malaria in expatriates in an intensive care unit in Abidjan (Ivory Coast). . Annales francaises d'anesthesie et de reanimation. 2002; 21(5):359-64.

12. Eholie SP, et al. Severe malaria in native adults in Abidjan (Cote d'Ivoire). . Bulletin de la Societe de pathologie exotique, . 2004;97(5):340-4.

13. Ahsan $T$, et al. Jaundice in falciparum malaria; changing trends in clinical presentation-a need for awareness. JPMA. The Journal of th e Pakistan Medical Association 2008;58(11) :616-21.

14. Kochar DK, et al. . The changing spectrum of severe falciparum malaria: a clinical study from Bikaner (northwest India). . Journal of vector borne diseases. 200 6;4 3 (3 ):104-8.

15. Ajetunmobi WA OA, Brown BJ. Haemoglobinuria among children with severe malaria attending tertiary care in Ibadan, Nigeria. . Malar J. 2012;11:336.

16. Gbadoe' AD K-CM, Koffi S. Evolution of severe pediatric malaria in Togo between 2000 and 2002. Med Mal Infect. 2006;36:52-4.

17. Kunuanunua TS, et al. Severe malaria in children: A descriptive report from Kinshasa, the Democratic Republic of Congo. J Trop Pediatr. 2015.

18. Rogier C, Imbert P, Tall A, Sokhna C, Spiegel A, Trape JF. Epidemiological and clinical aspects of blackwater fever among African children suffering frequent malaria attacks. Transactions of the Royal Society of Tropical Medicine and Hygiene. 2003;97(2):193-7. 
19. Malaria SEAQA. Artesunate versus quinine for treatment of severe falciparum malaria: a randomised trial. The Lancet. 2005;366(9487):717-25.

20. Dondorp AM, Lee SJ, Faiz MA, Mishra S, Price R, Tjitra E, et al. The relationship between age and the manifestations of and mortality associated with severe malaria. Clinical Infectious Diseases. 2008;47(2):151-7.

21. Hanson J, Lee SJ, Mohanty S, Faiz MA, Anstey NM, Charunwatthana Pk, et al. A simple score to predict the outcome of severe malaria in adults. Clinical infectious diseases. 2010;50(5):679-85.

22. Olowu WA, Adelusola KA. Pediatric acute renal failure in southwestern Nigeria. Kidney international. 2004;66(4):1541-8.

23. Okiro EA, Alegana VA, Noor AM, Snow RW. Changing malaria intervention coverage, transmission and hospitalization in Kenya. Malaria journal. 2010;9(1):1-13.

24. Okiro EA, Bitira D, Mbabazi G, Mpimbaza A, Alegana VA, Talisuna AO, et al. Increasing malaria hospital admissions in Uganda between 1999 and 2009. BMC medicine. 2011;9(1):1-11.

25. Barnes KI, Durrheim DN, Little F, Jackson A, Mehta U, Allen E, et al. Effect of artemether-lumefantrine policy and improved vector control on malaria burden in KwaZulu-Natal, South Africa. PLoS Med. 2005;2(11):e330.

26. Chizema-Kawesha E, Miller JM, Steketee RW, Mukonka VM, Mukuka C, Mohamed AD, et al. Scaling up malaria control in Zambia: progress and impact 2005-2008. The American journal of tropical medicine and hygiene. 2010;83(3):480-8.

27. Nyarango PM, Gebremeskel T, Mebrahtu G, Mufunda J, Abdulmumini U, Ogbamariam A, et al. A steep decline of malaria morbidity and mortality trends in Eritrea between 2000 and 2004: the effect of combination of control methods. Malaria journal. 2006;5(1):1-13.

28. Okiro EA, Hay SI, Gikandi PW, Sharif SK, Noor AM, Peshu N, et al. The decline in paediatric malaria admissions on the coast of Kenya. Malaria journal. 2007;6(1):1-11.

29. O'Meara WP, Bejon P, Mwangi TW, Okiro EA, Peshu N, Snow RW, et al. Effect of a fall in malaria transmission on morbidity and mortality in Kilifi, Kenya. The lancet. 2008;372(9649):1555-62.

30. Organization WH. World malaria report 2020: 20 years of global progress and challenges. 2020.

31. Kunuanunua TS, Nsibu CN, Bodi JM, Tshibola TK, Makusi Bura M, Magoga K, et al. Severe malaria in children: A descriptive report from Kinshasa, the Democratic Republic of Congo. Journal of tropical pediatrics. 2015.

32. Ajetunmobi WA, Orimadegun AE, Brown BJ, Afolabi NK, Olabiyi FA, Anetor JI, et al. Haemoglobinuria among children with severe malaria attending tertiary care in Ibadan, Nigeria. Malar J. 2012;11:336.

33. von Seidlein L, Olaosebikan R, Hendriksen IC, Lee SJ, Adedoyin OT, Agbenyega T, et al. Predicting the clinical outcome of severe falciparum malaria in african children: findings from a large randomized trial. Clin Infect Dis. 2012;54(8):1080-90.

34. Olupot-Olupot P, Engoru C, Uyoga S, Muhindo R, Macharia A, Kiguli S, et al. High frequency of blackwater fever among children presenting to hospital with severe febrile illnesses in eastern 
Uganda. Clinical Infectious Diseases. 2017;64(7):939-46.

35. Chau TTH, Day NP, Van Chuong L, Mai NTH, Loc PP, Phu NH, et al. Blackwater fever in southern Vietnam: a prospective descriptive study of 50 cases. Clinical infectious diseases. 1996;23(6):127481.

36. Foy $\mathrm{H}$, Kondi A. The correlation between blackwater fever, malaria, quinine and atebrin. Annals of Tropical Medicine \& Parasitology. 1950;44(4):309-18.

37. Hillmen P, Hall C, Marsh JCW, Elebute M, Bombara MP, Petro BE, et al. Effect of Eculizumab on Hemolysis and Transfusion Requirements in Patients with Paroxysmal Nocturnal Hemoglobinuria. New England Journal of Medicine. 2004;350(6):552-9.

38. Olupot-Olupot P, Engoru C, Nteziyaremye J, Chebet M, Ssenyondo T, Muhindo R, et al. The clinical spectrum of severe childhood malaria in Eastern Uganda. Malaria Journal. 2020;19(1):1-9.

39. Olupot-Olupot P, Engoru C, Uyoga S, Muhindo R, Macharia A, Kiguli S, et al. High frequency of blackwater fever among children presenting to hospital with severe febrile illnesses in Eastern Uganda. 2017;64(7):939-46.

40. Olupot-Olupot P. The Burden and Spectrum of Paediatric Severe Malaria and Aetiology of Dark Urine Syndrome in Eastern Uganda. : The Open University; 2015.

41. Opoka RO, Waiswa A, Harriet N, John CC, Tumwine JK, Karamagi C. Blackwater fever in Ugandan children with severe anemia is associated with poor postdischarge outcomes: a prospective cohort study. Clinical Infectious Diseases. 2019.

42. Bodi JM, Nsibu CN, Longenge RL, Aloni MN, Akilimali PZ, Tshibassu PM, et al. Blackwater fever in Congolese children: a report of clinical, laboratory features and risk factors. Malar J. 2013;12:205.

43. Mockenhaupt FP ES, Burkhardt J, Bosomtwe SY, Laryea S, Anemana SD. Manifestation and outcome of severe malaria in children in Northern Ghana. . Am J Trop Med Hyg. 2004; 71:167-72

44. Imbert P, Sartelet I, Rogier C, Ka S, Baujat G, Candito D. Severe malaria among children in a low seasonal transmission area, Dakar, Senegal: influence of age on clinical presentation. Transactions of the Royal Society of Tropical Medicine and Hygiene. 1997;91(1):22-4.

45. Modiano D, Sirima B, Sawadogo A, Sanou I, Pare J, Konate A, et al. Severe malaria in Burkina Faso: influence of age and transmission level on clinical presentation. The American journal of tropical medicine and hygiene. 1998;59(4):539-42.

46. Snow R, De Azevedo IB, Lowe B, Kabiru E, Nevill C, Mwankusye S, et al. Severe childhood malaria in two areas of markedly different falciparum transmission in east Africa. Acta tropica. 1994;57(4):289300.

47. Snow RW, Omumbo JA, Lowe B, Molyneux CS, Obiero J-O, Palmer A, et al. Relation between severe malaria morbidity in children and level of Plasmodium falciparum transmission in Africa. The lancet. 1997;349(9066):1650-4.

48. Doumbo OK, Thera MA, Koné AK, Raza A, Tempest LJ, Lyke KE, et al. High levels of Plasmodium falciparum rosetting in all clinical forms of severe malaria in African children. The American journal of tropical medicine and hygiene. 2009;81(6):987-93. 
49. Rowe A, Obeiro J, Newbold Cl, Marsh K. Plasmodium falciparum rosetting is associated with malaria severity in Kenya. Infection and immunity. 1995;63(6):2323-6.

50. Rogier C IP, Tall A, Sokhna C, Spiegel A, Trape JF. . Epidemiological and clinical aspects of blackwater fever among African children suffering frequent malaria attacks. Trans R Soc Trop Med Hyg. 2003; 97:193-7.

51. Nabikolo D, Bashaasha B, Mangheni M, Majaliwa J. Determinants of climate change adaptation among male and female headed farm households in eastern Uganda. African Crop Science Journal. 2012;20:203-12.

52. Alex N, Jesse K, Neoline N. Evaluation of past and future extreme rainfall characteristics over eastern Uganda. J Environ Agric Sci. 2019;18:38-49.

53. Health UMo. Uganda clinical guidelines 2016. Kampala, Uganda: Uganda Ministry of Health; 2016.

54. Mpoya A, Kiguli S, Olupot-Olupot P, Opoka RO, Engoru C, Mallewa M, et al. Transfusion and Treatment of severe anaemia in African children (TRACT): a study protocol for a randomised controlled trial. Trials. 2015;16(1):1-15.

55. Maitland K, Olupot-Olupot P, Kiguli S, Chagaluka G, Alaroker F, Opoka RO, et al. Co-trimoxazole or multivitamin multimineral supplement for post-discharge outcomes after severe anaemia in African children: a randomised controlled trial. The Lancet Global Health. 2019;7(10):e1435-e47.

56. Bodi JM, Nsibu CN, Aloni MN, Lukute GN, Kunuanuna TS, Tshibassu PM, et al. Black water fever associated with acute renal failure among Congolese children in Kinshasa. Saudi Journal of Kidney Diseases and Transplantation. 2014;25(6):1352.

\section{Figures}




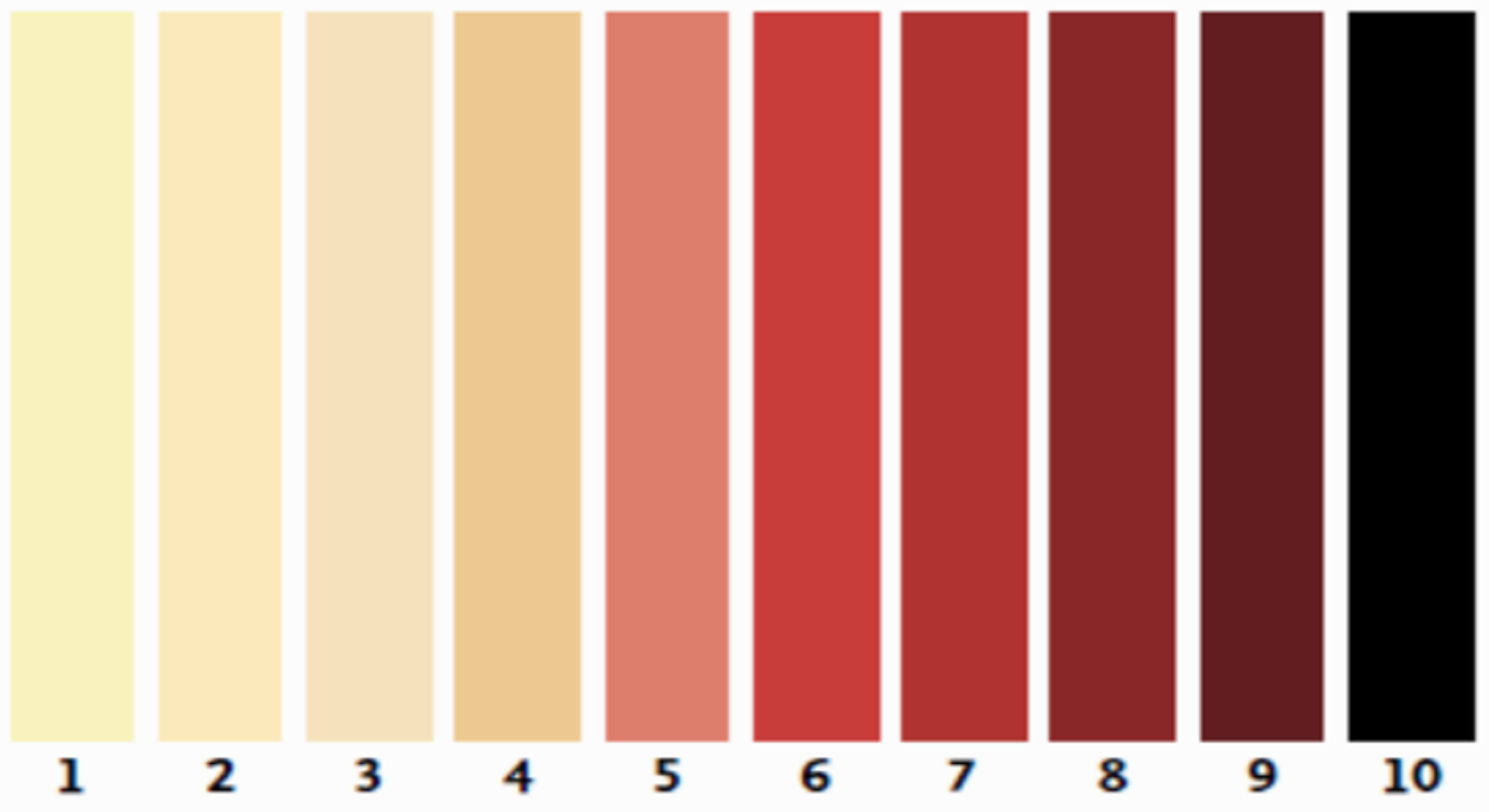

Figure 1

The Hillmen Urine Colour Chart

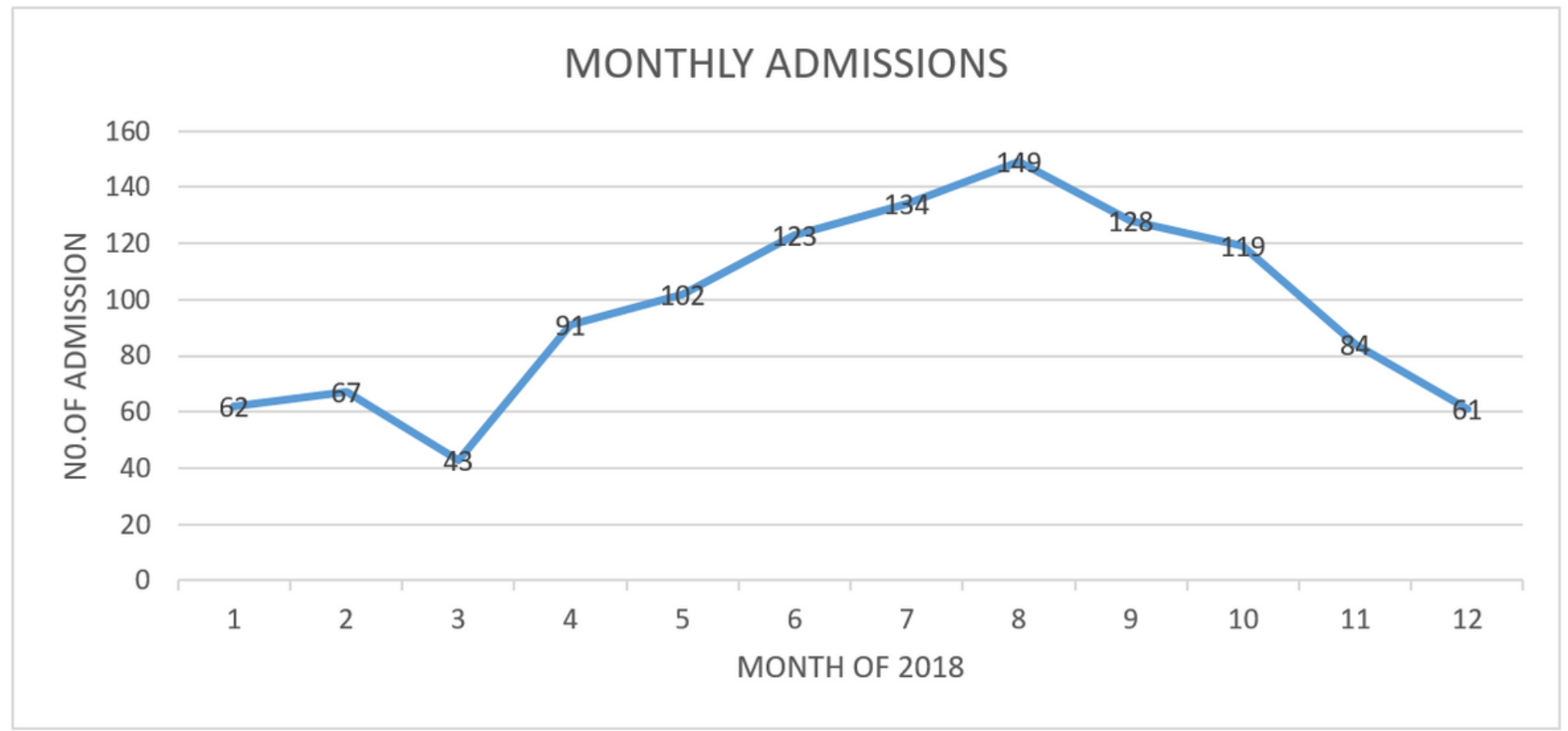

Figure 2

Pattern of monthly admissions of BWF cases in 2018 


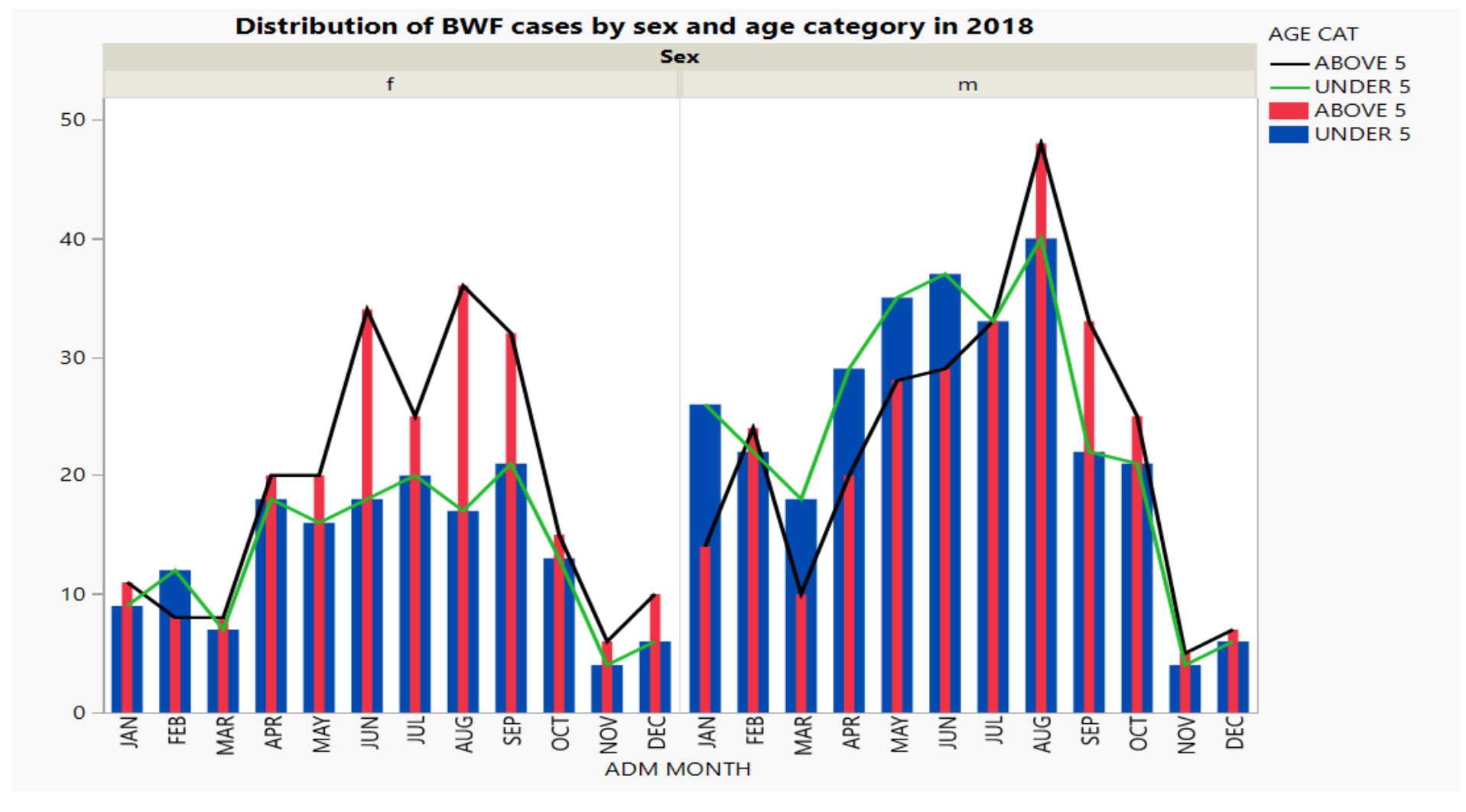

Figure 3

Seasonal variation of BWF cases by sex and age category in 2018 . 